\title{
Hydrodechlorination of tetrachloromethane over silica-supported palladium-gold alloys
}

\author{
Zbigniew Karpiński ${ }^{1,2,}$, Magdalena Bonarowska ${ }^{1}$, Wojciech Juszczyk ${ }^{1}$ \\ ${ }^{1}$ Institute of Physical Chemistry of the Polish Academy of Sciences, ul. Kasprzaka 44/52, PL-01224 Warszawa, Poland \\ ${ }^{2}$ Cardinal Stefan Wyszyński University in Warsaw, Faculty of Mathematics and Natural Sciences-School of Science, \\ ul. Wóycickiego 1/3, PL-01938 Warszawa, Poland \\ "Corresponding author: e-mail: zkarpinski@ichf.edu.pl
}

This article is dedicated to Professor Walerian Arabczyk on the occasion of his 70th birthday.

Compared with the monometallic palladium, bimetallic $\mathrm{Pd}-\mathrm{Au} / \mathrm{SiO}_{2}$ catalysts show much higher activity and better stability in the reaction of hydrodechlorination of tetrachloromethane, also providing higher selectivity to longer than methane hydrocarbon products. Reasonably mixed Pd-Au particles show better catalytic performance during $\sim 60 \mathrm{~h}$ operation, whereas the monometallic palladium and very rich in palladium catalysts suffer rapid deactivation. Smaller amounts of carbon- and chlorine-containing deposits found after reaction on Pd-Au catalysts correspond to their superior catalytic behavior.

Keywords: $\mathrm{Pd}-\mathrm{Au} / \mathrm{SiO}_{2}, \mathrm{CCl}_{4}$ hydrodechlorination, synergy, selectivity for hydrocarbons, catalyst deactivation.

\section{INTRODUCTION}

Catalytic hydrodechlorination $(\mathrm{HdCl})$ is regarded as one of the most prospective methods of destruction of harmful chlorine-containing compounds, ${ }^{\mathbf{1}}$. Compared to incineration and catalytic burning, which destroy the carbon skeleton material and would result in the formation of even more harmful compounds (dioxins, phosgene, etc.), $\mathrm{HdCl}$ offers the transformation to more benign and still valuable chemicals. Until recently, $\mathrm{HdCl}$ of tetrachloromethane to chloroform carried out in the presence of Pt-based catalysts was regarded as a suitable method $^{3-5}$, but now the high toxic and carcinogenic character of $\mathrm{CHCl}_{3}$ placed this substance in the U.S. EPA's Toxic Release Inventory (TRI). Therefore, conversion of $\mathrm{CCl}_{4}$ to hydrocarbons appears now a more reasonable solution. In contrast to platinum, palladium catalysts were found useful in such transformation, however they quickly deactivate on stream ${ }^{6-10}$. Interestingly enough, Pd-Au bimetallic nano-particles were recently discovered to exhibit superior catalyst activity and improved deactivation resistance in $\mathrm{HdCl}$ of chlorinated ethenes ${ }^{11-13}$. In this report we present new data on the catalytic behavior of $\mathrm{Pd}-\mathrm{Au} / \mathrm{C}$ and $\mathrm{Pd}-\mathrm{Au} / \mathrm{SiO}_{2}$ catalysts in $\mathrm{HdCl}$ of $\mathrm{CCl}_{4}$.

\section{EXPERIMENTAL}

The support was Davison 62 silica gel, 75-120 mesh, precalcined in air at $450^{\circ} \mathrm{C}$ for $3 \mathrm{~h}$. The $2 \mathrm{wt} \% \mathrm{Pd} / \mathrm{SiO}_{2}$ catalyst was prepared by impregnation of silica with an aqueous solution of palladium dichloride (analytical reagent from POCh Gliwice, Poland), using an incipient wetness technique. After impregnation, the solid was dried in an air at $120^{\circ} \mathrm{C}$ for $6 \mathrm{~h}$. After drying, the material was precalcined in a fluidized bed in an air flow from room temperature to $450^{\circ} \mathrm{C}$ at a $2 \mathrm{deg} . / \mathrm{min}$ ramp and maintained at $450^{\circ} \mathrm{C}$ for $3 \mathrm{~h}$. After cooling down, the precursor was flushed out with argon and reduced in a $50 \% \mathrm{H}_{2} / \mathrm{Ar}$ stream from room temperature to $400^{\circ} \mathrm{C}$ (a 4 deg./min ramp) and kept at $400^{\circ} \mathrm{C}$ for $3 \mathrm{~h}$. After reduction and passivation in air (at room temperature) the catalyst was kept in a desiccator.

The bimetallic silica-supported palladium-gold catalysts were prepared by sequential reduction impregnation ${ }^{14}$.
The monometallic $\mathrm{Pd} / \mathrm{SiO}_{2}$ catalyst was prereduced at $300^{\circ} \mathrm{C}$ for $3 \mathrm{~h}$ in a special reactor in flowing $\mathrm{H}_{2}-\mathrm{Ar}$ $\left(300 \mathrm{~cm}^{3} / \mathrm{min}\right)$, then purged in an argon flow at $300^{\circ} \mathrm{C}$ for $1 \mathrm{~h}$, cooled to room temperature in $\mathrm{Ar}$, and, finally, immersed in de-aerated doubly distilled water. The solution was continuously stirred by bubbling argon, at $200 \mathrm{~cm}^{3} / \mathrm{min}$. Then, a de-aerated aqueous solution of ammonium chloroaurate (Johnson Matthey, specpure) was slowly introduced into the reactor. The solution was stirred with bubbling argon for the next $20 \mathrm{~min}$. The resulting solid was separated by filtration, washed with redistilled water, and dried in flowing argon at $60^{\circ} \mathrm{C}$ for overnight, and finally stored in a desiccator. Three bimetallic $\mathrm{Pd}-\mathrm{Au} / \mathrm{SiO}_{2}$ catalysts were prepared in this manner. Their basic characteristics, after reduction in hydrogen at $400^{\circ} \mathrm{C}$ for $3 \mathrm{~h}$, along with designation are in Table 1. Metal dispersion was assessed by $\mathrm{CO}$ and $\mathrm{H}_{2}$ chemisorption (details in Table 1). After $\mathrm{H}_{2}$ chemisorption, the samples were cooled to $\sim 0^{\circ} \mathrm{C}$ in $\mathrm{H}_{2} / \mathrm{Ar}$ flow (to be transformed into respective $\mathrm{Pd}(\mathrm{Au}) \mathrm{H}$ phases). Next, they were heated to $\sim 150^{\circ} \mathrm{C}$, at the temperature ramp of $8 \mathrm{deg} . / \mathrm{min}$. Such runs, called temperature-programmed hydride decomposition (TPHD), carried out in $10 \%$ $\mathrm{H}_{2} / \mathrm{Ar}_{\text {mixture }} \mathrm{i}^{15}$ are supposed to reveal the stability and composition of the $\beta$-hydride phase as a function of gold content in palladium.

Table 1. Catalyst characterization - designation, palladium dispersion by chemisorption and temperature-programmed hydride decomposition (TPHD) data

\begin{tabular}{|l|c|c|c|c|}
\hline \multirow{2}{*}{ Catalyst } & \multicolumn{2}{|c|}{$\mathrm{Pd}$ dispersion } & \multicolumn{2}{c|}{$\begin{array}{c}\text { Temperature programmed } \\
\text { hydride decomposition }\end{array}$} \\
\cline { 2 - 5 } & $\mathrm{CO} / \mathrm{Pd}^{\mathrm{a}}$ & $\mathrm{H} / \mathrm{Pd}^{\mathrm{c}}$ & $\mathrm{H} / \mathrm{Pd}^{\mathrm{d}}$ & $\mathrm{T}_{\max },{ }^{\circ} \mathrm{C}^{\mathrm{e}}$ \\
\hline $2.0 \% \mathrm{Pd}_{100}$ & 0.268 & 0.21 & 0.233 & 59.9 and 80.5 \\
\hline $2.2 \% \mathrm{Pd}_{95} \mathrm{Au}_{5}$ & 0.075 & 0.07 & 0.201 & 61.0 and 81.0 \\
\hline $2.2 \% \mathrm{Pd}_{80} \mathrm{Au}_{20}$ & 0.071 & 0.025 & 0.198 & 67.6 and 82.7 \\
\hline $2.7 \% \mathrm{Pd}_{60} \mathrm{Au}_{40}$ & 0.039 & 0.012 & 0.156 & 72.8 and 86.0 \\
\hline
\end{tabular}

a $\mathrm{X} \%$ denotes total metal $(\mathrm{Pd}+\mathrm{Au}$ ) loading in wt.\% (assesed by atomic absorption), whereas in $\mathrm{Pd}_{\mathrm{Y}} \mathrm{Au}_{100-\mathrm{Y}}, \mathrm{Y}$ stands for atom $\%$ of palladium in the metal phase,

${ }^{b}$ from CO chemisorption measured in a static system at $35^{\circ} \mathrm{C}$, ${ }^{c}$ from $\mathrm{H}_{2}$ chemisorption measured in a pulse-flow system at $70^{\circ} \mathrm{C}$, ${ }^{\mathrm{d}} \mathrm{H} / \mathrm{Pd}$ ratio from the amount of hydrogen released in palladium hydride decomposition,

e Positions of temperature maxima of TPHD profiles. 
Reduced catalyst samples were investigated by X-ray diffractometry (Rigaku Denki, Ni-filtered $\mathrm{CuK}_{\alpha}$ radiation). One selected, the most promising $\mathrm{Pd}-\mathrm{Au}$ catalyst was also investigated by high resolution transmission electron microscopy studies, using a FEI Titan Cubed at $300 \mathrm{kV}$ accelerating voltage.

The reaction of hydrodechlorination of tetrachloromethane (analytical reagent from POCh, Gliwice, Poland, purity $>99.6 \%$ ) at $90^{\circ} \mathrm{C}$ and the $\mathrm{H}_{2}: \mathrm{CCl}_{4}$ ratio $\sim 14: 1$ was carried out in a glass flow system, previously described ${ }^{\mathbf{1 6}, 17}$. The flows of $\mathrm{H}_{2}$ and diluting $\mathrm{Ar}$ (all $99.999 \%$ pure, further purified by passing through $\mathrm{MnO} / \mathrm{SiO}_{2}$ traps), were preset by using mass flow controllers (Bronkhorst Hi-Tec). Prior to reaction, the catalyst samples were reduced at $400^{\circ} \mathrm{C}$ for $3 \mathrm{~h}$. A typical run lasted 60-70 hours. 2 wt. $\% \mathrm{Au} / \mathrm{SiO}_{2}$ catalyst was not active in this reaction and it is not included into description of results and discussion.

Post-reaction catalyst samples were also investigated by temperature programmed hydrogenation (TPH-MS). TPH-MS runs were carried out in a flowing $10 \% \mathrm{H}_{2} /$ He mixture $\left(25 \mathrm{~cm}^{3} / \mathrm{min}\right)$ at a $10 \mathrm{deg} . / \mathrm{min} \mathrm{ramp}$ and followed by mass spectrometry (MA200, Dycor-Ametek, Pittsburgh, USA). Principal attention was paid to $\mathrm{m} / \mathrm{z} 15$ and 16 (methane evolution), and $\mathrm{m} / \mathrm{z} 36$ and 38, which are suggestive of $\mathrm{HCl}$ liberation from catalysts used.

\section{RESULTS AND DISCUSSION}

The results of catalysts' characterization are shown in Table 1 and Figures 1, 2 and 3. It is seen that the prepared catalysts are characterized by medium metal dispersion. The monometallic $\mathrm{Pd} / \mathrm{SiO}_{2}$ catalyst showed the crystallite size of $\sim 5 \mathrm{~nm}$ (by XRD, Fig. 1), in agreement with a predicted metal particle size assessed from chemisorption $\left(\mathrm{d}_{\mathrm{nm}}=1.12 /\right.$ dispersion $\left.^{\mathbf{1 8}}\right)$. Lower, in comparison with the monometallic $\mathrm{Pd} / \mathrm{SiO}_{2}$, palladium dispersions in $\mathrm{Pd}-\mathrm{Au} / \mathrm{SiO}_{2}$ catalysts, judged from lower gas uptakes, most probably result from a surface segregation of gold. In such a case surface composition of palladium is lower than its bulk content, which served for determination of $\mathrm{H} / \mathrm{Pd}$ and $\mathrm{CO} / \mathrm{Pd}$ ratios for the bimetallics ${ }^{19}$.

The XRD profiles (Fig. 1) of reduced $\mathrm{Pd}-\mathrm{Au} / \mathrm{SiO}_{2}$ catalysts showed a reasonable, although not full, degree of $\mathrm{Pd}-\mathrm{Au}$ alloying. The dominant part of the material contributes to the occurrence of single, relatively narrow XRD reflections.

But some inhomogeneity of the prepared material was manifested in the profiles of the temperature programmed hydride decomposition (TPHD) experiments, Figure 2. Two maxima found for TPHD of the monometallic $\mathrm{Pd} / \mathrm{SiO}_{2}$ show that this catalyst contains two metallic fractions characterized by smaller and larger metal particles ${ }^{20}$. Introduction of gold to $\mathrm{Pd} / \mathrm{SiO}_{2}$ smoothly shifts these maxima towards higher temperatures, suggesting similar modification for both palladium fractions. It has to be remarked that such shifts are consistent with an earlier observation of Ziemecki et al. ${ }^{21}$ who found that a commercial $\mathrm{Pd}-\mathrm{Au}$ powder (of $20 \mathrm{wt} . \% \mathrm{Pd}$ ) showed a TPHD peak at the temperature $\sim 35^{\circ} \mathrm{C}$, higher than that exhibited for a physical mixture of $\mathrm{Pd}$ and $\mathrm{Au}$ powders.

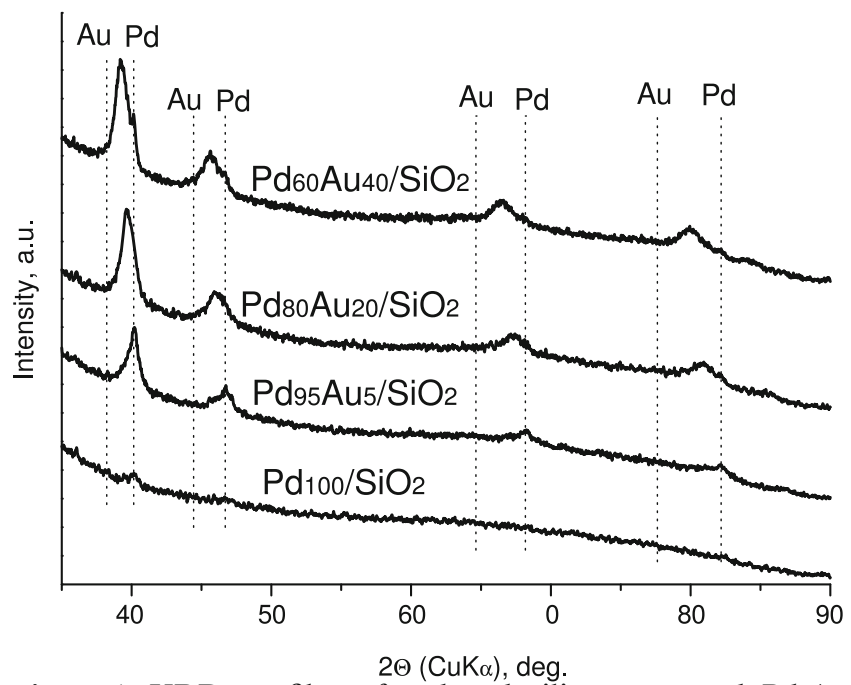

Figure 1. XRD profiles of reduced silica-supported Pd-Au catalysts. Basic XRD reflections from palladium and gold are marked. For catalyst designation see Table 1

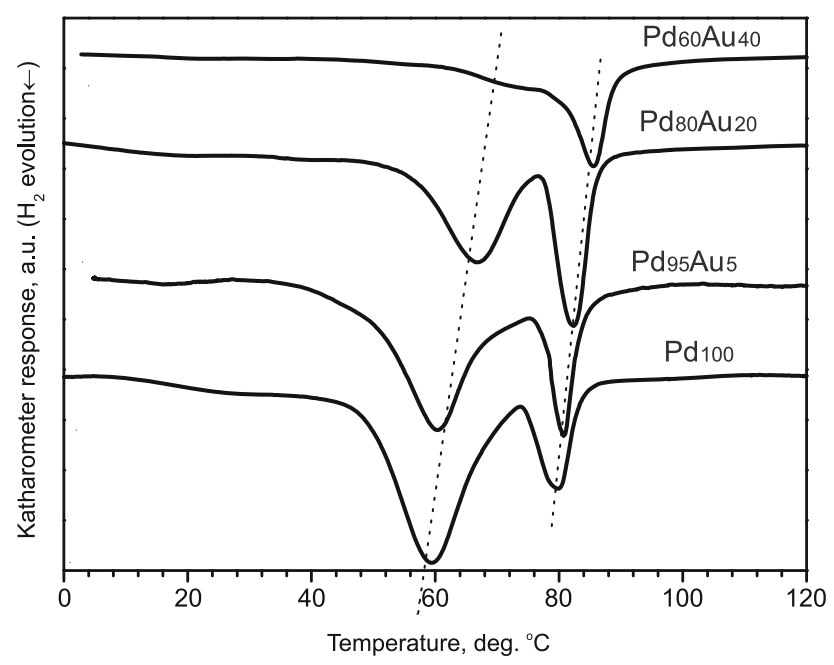

Figure 2. Temperature programmed (palladium) hydride decomposition (TPHD) profiles from silica-supported $\mathrm{Pd}-\mathrm{Au}$ catalysts. For catalyst designation see Table 1

Our TEM studies show that, apart from smaller metal particles $(\sim 5-10 \mathrm{~nm})$, larger alloy particles are also present in $\mathrm{Pd}_{60} \mathrm{Au}_{40} / \mathrm{SiO}_{2}(15-20 \mathrm{~nm})$, Figure 3. This confirms conclusions drawn from the TPHD studies about the size heterogeneity of our metal particles.

Figure 4 shows changes in the overall catalytic activity for silica supported $\mathrm{Pd}-\mathrm{Au}$ catalysts with time on stream. It is evident that a gradual increase of $\mathrm{Au}$ content contributes to a more stable behavior. Both $\mathrm{Pd}_{100}$ and $\mathrm{Pd}_{95} \mathrm{Au}_{5}$ catalysts show rapid deactivation, accompanied by an increase of formation of dimeric $\mathrm{C}_{2} \mathrm{H}_{\mathrm{x}} \mathrm{Cl}_{\mathrm{y}}$ products. At the end of catalytic run, when these catalysts are nearly inactive because their surfaces are largely blocked by deposits, methane formation dominates over other products. The performance of $\mathrm{Pd}_{80} \mathrm{Au}_{20}$ and $\mathrm{Pd}_{60} \mathrm{Au}_{40}$ differ much from that exhibited by $\mathrm{Pd}_{100}$. Now the deactivation is found much less serious. This situation must follow from a higher content of gold on the surface of palladium containing catalysts. It must be noticed that even the initial (not only final) activities of $\mathrm{Pd}_{80} \mathrm{Au}_{20}$ and $\mathrm{Pd}_{60} \mathrm{Au}_{40}$ are much higher than that of $\mathrm{Pd}_{100}$, especially after considering much lower palladium dispersions in bimetallic catalysts. The fact that a relatively fresh (not 


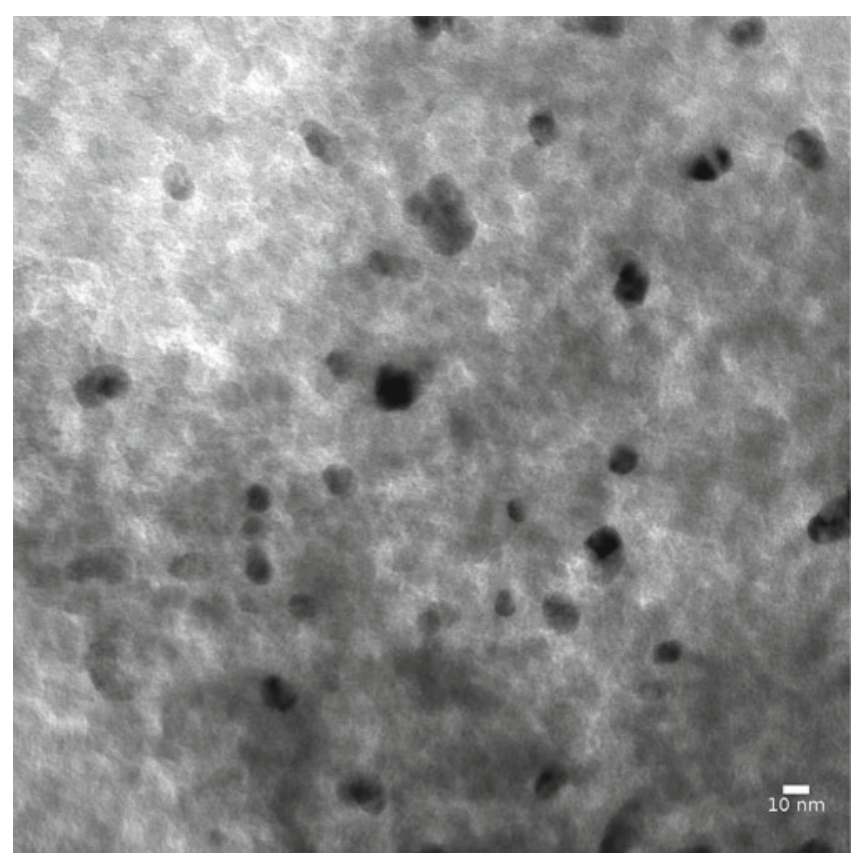

Figure 3. TEM micrograph of reduced $\mathrm{Pd}_{60} \mathrm{Au}_{40} / \mathrm{SiO}_{2}$ catalyst

blocked by deposits) surface of Pd-Au catalysts is more active than that of pure palladium suggests the occurrence of ligand effect, understood as an electronic modification of "too active" surface Pd atoms by neighboring gold species $^{22}$. Changing the $\mathrm{d}$ character of Pd would cause weaker interaction between surface palladium and reactant/product molecules. On the other hand, much better resistance to deactivation by deposited chlorine- and
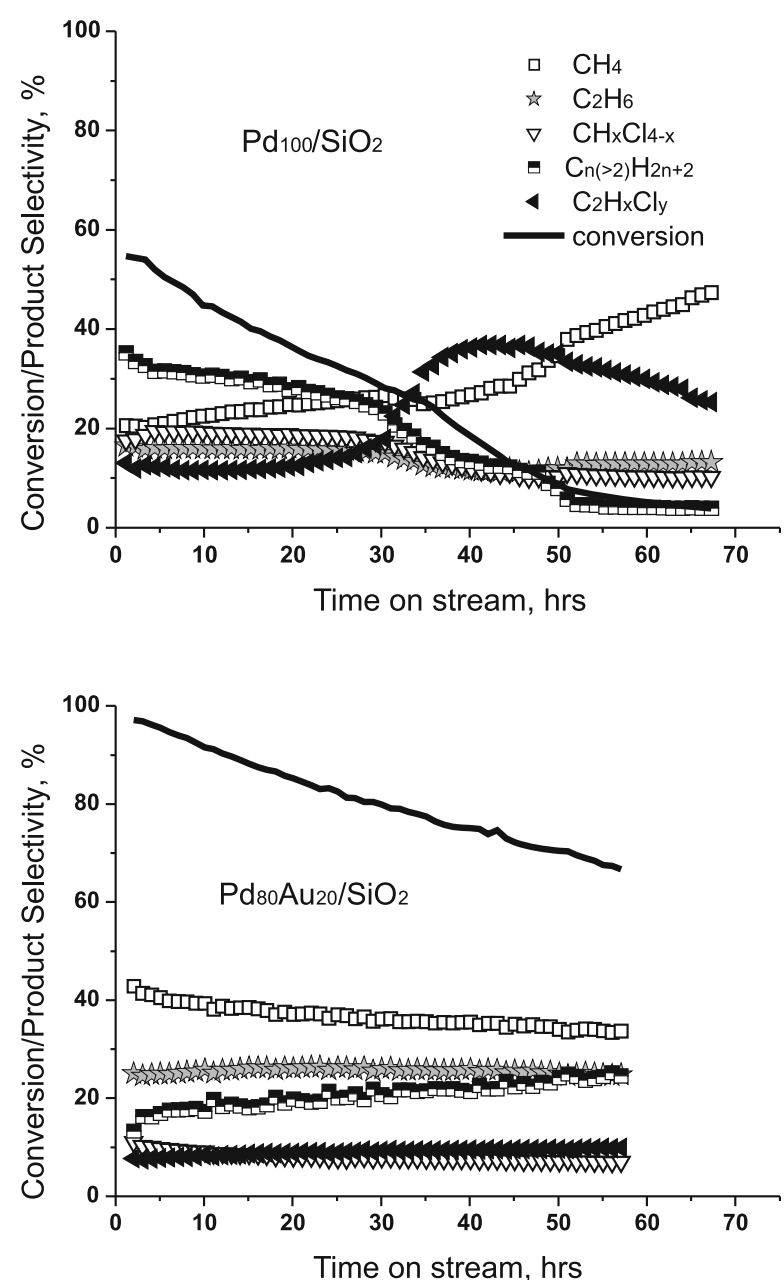

carbon-containing species (vide infra) suggests operation of the ensemble effect, when the contiguity of active palladium sites is interrupted by diluting gold ${ }^{22}$.

Table 2 collects the overall activity and selectivity data for all tested catalysts. It is seen that although gold itself is inactive in $\mathrm{HdCl}$ of $\mathrm{CCl}_{4}$, its addition to Pd vastly increases the selectivity to hydrocarbons, which are desired reaction products. Remarkably, $\mathrm{Pd}_{80} \mathrm{Au}_{20}$ and $\mathrm{Pd}_{60} \mathrm{Au}_{40}$ also produce much larger amounts of $\mathrm{C}_{2+}$ hydrocarbons, which are the most desired products.

Figure 5 shows that the post-reaction deposits have mainly chlorine-containing species. Their amount seems to be inversely correlated with the gold content. So, the degree of catalyst deactivation must be linked to the gold content. Figure 5 also shows that although carbonaceous deposits are much less plentiful than surface chloride species, their removal needs much higher temperatures, $\sim 600^{\circ} \mathrm{C}$. Therefore, their influence on catalyst deactivation would also be significant.

It seems that main role of gold is understood in an improved deactivation resistance in $\mathrm{HdCl}$ of $\mathrm{CCl}_{4}$. Also, larger amounts of stripped surface chlorine from the surface of Pd-Au catalysts during reaction would explain their better selectivity to hydrocarbons. It should be mentioned that palladium modification with another Group IB metal, copper, brings about positive changes in product selectivity, i.e. yielding more hydrocarbons than on pure $\mathrm{Pd}^{23}$. However, the presence of copper, although beneficial for the selectivity, does not improve the poor stability of palladium catalysts. Massive retention
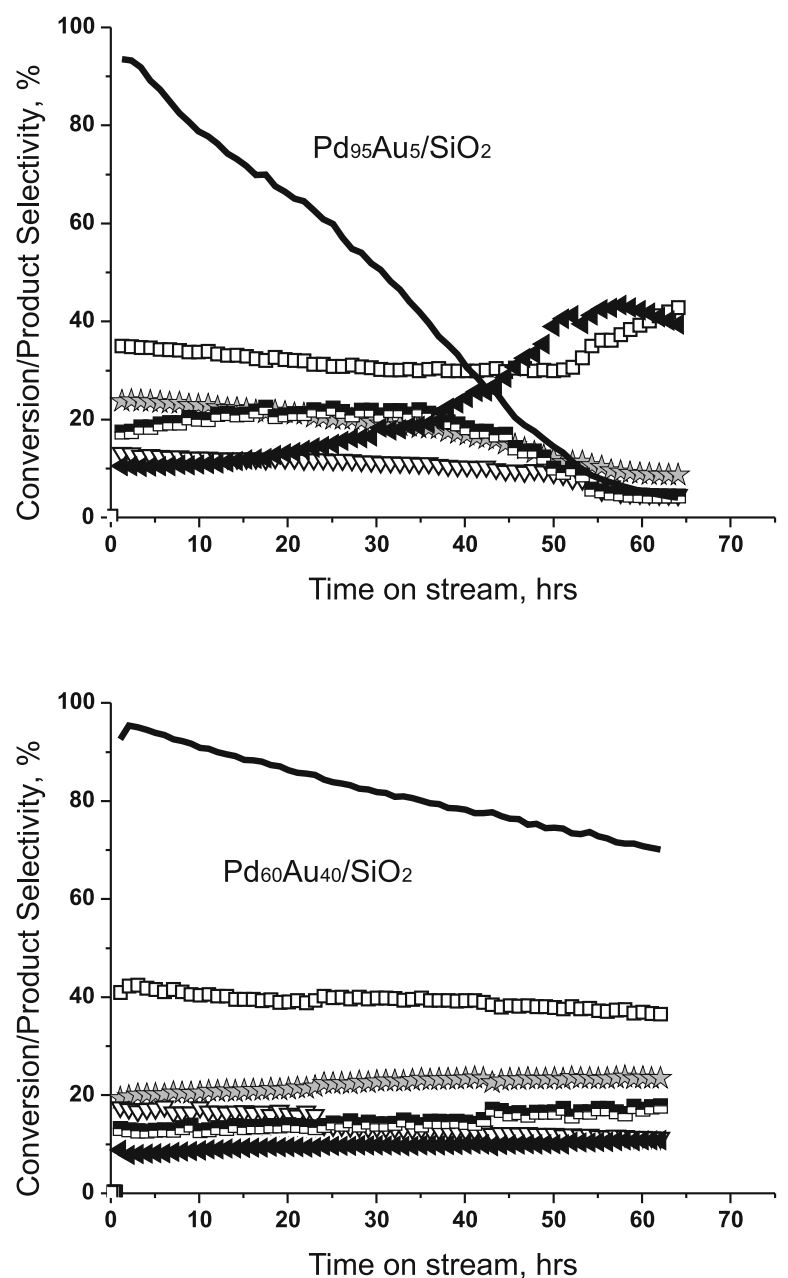

Figure 4. Time on stream behavior of silica-supported $\mathrm{Pd}$-Au catalysts in the hydrodechlorination of $\mathrm{CCl}_{4}$. Reaction temperature $90^{\circ} \mathrm{C}, \mathrm{H}_{2} / \mathrm{CCl}_{4}=14$, catalyst weight $0.24 \mathrm{~g}$. For catalyst designation see Table 1 
Table 2. Catalytic performance of $\mathrm{Pd}-\mathrm{Au} / \mathrm{SiO}_{2}$ catalysts in the reaction of $\mathrm{CCl}_{4}$ hydrodechlorination (after $60-70$ hours of reaction at $\left.90^{\circ} \mathrm{C}\right)$.

\begin{tabular}{|l|c|c|c|c|c|c|c|}
\hline \multirow{2}{*}{ Catalyst $^{\mathrm{a}}$} & \multirow{2}{*}{ Conversion, [\%] } & \multicolumn{5}{|c|}{ Product selectivity, [\%] } \\
\cline { 3 - 8 } & & $\mathrm{CH}_{4}$ & $\mathrm{C}_{2} \mathrm{H}_{6}$ & $\mathrm{CH}_{3} \mathrm{Cl}$ & $\mathrm{CHCl}_{3}$ & $\mathrm{C}_{n(2)} \mathrm{H}_{2 n+2}$ & $\mathrm{C}_{2} \mathrm{H}_{\mathbf{x}} \mathrm{Cl}_{\mathrm{y}}$ \\
\hline $2.0 \% \mathrm{Pd}_{100}$ & 4 & 47 & 13 & 6 & 4 & 4 & 25 \\
\hline $2.2 \% \mathrm{Pd}_{95} \mathrm{Au}_{5}$ & 4 & 43 & 9 & 5 & - & 4 & 39 \\
\hline $2.2 \% \mathrm{Pd}_{80} \mathrm{Au}_{20}$ & 67 & 34 & 25 & 5 & 2 & 24 & 10 \\
\hline $2.7 \% \mathrm{Pd}_{60} \mathrm{Au}_{40}$ & 70 & 36 & 23 & 9 & 2 & 18 & 11 \\
\hline
\end{tabular}

a as in Table 1.

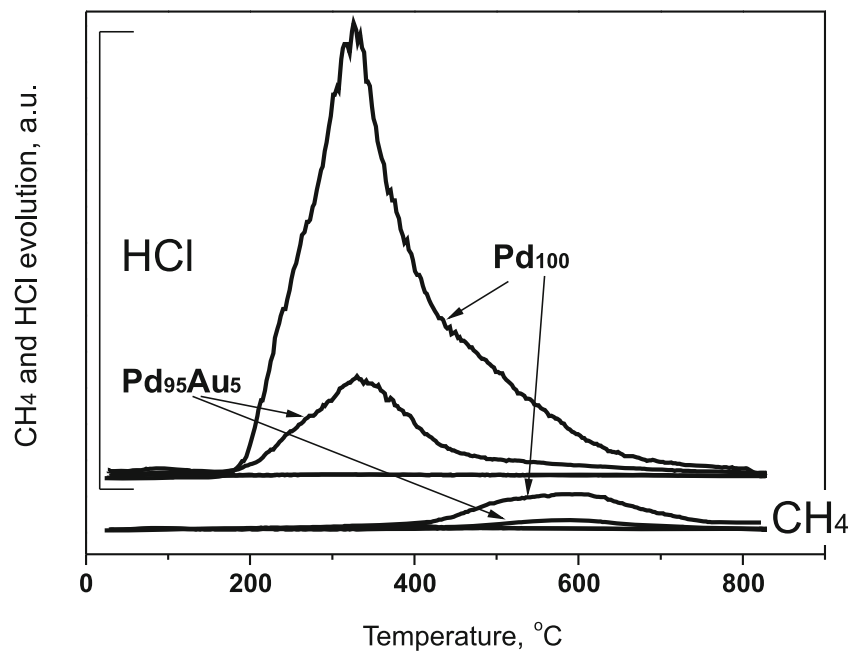

Figure 5. Temperature programmed hydrogenation profiles of postreaction deposits from silica-supported $\mathrm{Pd}$ and $\mathrm{Pd}-\mathrm{Au}$ catalysts: upper profiles- $\mathrm{HCl}(\mathrm{m} / \mathrm{z} 36)$ and lower profiles - methane (m/z 16) evolution. Featureless horizontal lines were obtained for $\mathrm{Pd}_{80} \mathrm{Au}_{20}$ and $\mathrm{Pd}_{60} \mathrm{Au}_{40}$ indicating negligible deposition of chlorine and carbon containing species

of $\mathrm{C}_{2} \mathrm{H}_{\mathrm{x}} \mathrm{Cl}_{\mathrm{y}}$ species found after $\mathrm{HdCl}$ of 1,2-dichloroethane on $\mathrm{Pd}-\mathrm{Cu} / \mathrm{Sibunit}$ carbon catalysts ${ }^{24}$ would also be responsible for deactivation of $\mathrm{Pd}-\mathrm{Cu}$ catalysts in the reaction of $\mathrm{CCl}_{4}$.

\section{CONCLUSIONS}

Sequential impregnation of silica-supported palladium with the gold salt followed by reduction in hydrogen at $400^{\circ} \mathrm{C}$ results in a reasonable, although not full degree of Pd-Au alloying. Although gold itself is not active in tetrachloromethane hydrodechlorination at $90^{\circ} \mathrm{C}$, its introduction to palladium generates beneficial changes both in the overall activity and product selectivity, giving large amounts of longer hydrocarbons and relatively little amounts of heavier chlorine-containing compounds. Bimetallic $\mathrm{Pd}-\mathrm{Au} / \mathrm{SiO}_{2}$ catalysts are also much less susceptible to deactivation during long term operation (60-70 h). Post-reaction deposits contain both chloride as well as carbon species. However, their amounts are much less abundant on the surface of Pd-Au alloys than on pure palladium.

\section{ACKNOWLEDGMENT}

This work was supported by the National Science Centre within Research Project DEC-2011/01/B/ST5/03888 and also, in part, by the grant from the Polish Ministry of Science and Higher Education - decision 753/N-COST/2010/0.

\section{LITERATURE CITED}

1. Kovalchuk, V.I. \& d'Itri, J.L. (2004). Catalytic chemistry of chloro- and chlorofluorocarbon dehalogenation: from macroscopic observations to molecular level understanding. Appl. Catal. $A$ 271, 13-25. DOI: 10.1016/j.apcata.2004.02.042.

2. Keane, M.A. (2011). Supported transition metal catalysts for hydrodechlorination reactions. ChemCatChem 3, 800-821. DOI: $10.1002 /$ cctc. 201000432 .

3. Zhang, Z.C. \& Beard, B.C. (1998). Genesis of durable catalyst for selective hydrodechlorination of $\mathrm{CCl}_{4}$ to $\mathrm{CHCl}_{3}$. Appl. Catal. A 174, 33-39. http://dx.doi.org/10.1016/S0926860X(98)00150-1

4. Holbrook, M.T. \& Myers, J.D. (2007). U.S Patent No. 2007/0225530 A1. Washington, D.C.: U.S. Patent and Trademark Office.

5. Bonarowska, M., Kaszkur, Z., Kępiński, L. \& Karpiński, Z. (2010). Hydrodechlorination of tetrachloromethane on alumina- and silica-supported platinum catalysts. Appl. Catal. $B$ 99, 248-256. DOI: 10.1016/j.apcatb.2010.06.027.

6. Lokteva, E.S., Lunin, V.V., Golubina, E.V., Simagina, V.I., Egorova, M. \& Stoyanova, I.V. (2000). C-C bond formation during hydrodechlorination of $\mathrm{CCl}_{4}$ on Pd-containing catalysts. Stud. Surf. Sci. Catal. 130, 1997-2002.

7. Dal Santo, V., Dossi, C., Recchia, S., Colavita, P.E., Vlaic, G. \& Psaro, R. (2002). Carbon tetrachloride hydrodechlorination with organometallics-based platinum and palladium catalysts on MgO. J. Mol. Catal. A 182-183, 157-166. http:// dx.doi.org/10.1016/S1381-1169(01)00458-7

8. Szczepaniak, B., Góralski, J., Grams, J. \& Paryjczak, T. (2006). Studies on the activity of $\mathrm{Pd} / \mathrm{TiO}_{2}$ catalysts in the hydrodechlorination of $\mathrm{CCl}_{4}$. Przem. Chem. 85, 764-765.

9. Prati, L. \& Rossi, M. (1999). Reductive catalytic dehalogenation of light chlorocarbons. Appl. Catal. B 23, 135-142. http://dx.doi.org/10.1016/S0926-3373(99)00071-5

10. Grams, J., Góralski, J. \& Kwintal, P. (2010). ToFSIMS studies of the regeneration of $\mathrm{Pd} / \mathrm{TiO} 2$ catalyst used in hydrodechlorination process. Int. J. Mass Spectr. 292, 1-6. DOI: 10.1016/j.ijms.2010.02.006.

11. Wong, M.S., Alvarez, P.J.J., Fang, Y.L., Akçin, N., Nutt, M.O., Miller, J.T. \& Heck, K.N. (2009). Cleaner water using bimetallic nanoparticle catalysts. J. Chem. Technol. Biotechnol. 84, 158-166. DOI: 10.1002/jctb.2002.

12. Heck, K.N., Nutt, M.O., Alvarez, P. \& Wong, M.S. (2009). Deactivation resistance of Pd/Au nanoparticle catalysts for water-phase hydrodechlorination. J. Catal. 267, 97-104. DOI: 10.1016/j.jcat.2009.07.015.

13. Pretzer, L.A., Song, H.J., Fang, Y.-L., Zhao, Z., Guo, N., Wuc, T., Arslan, I., Miller, J.T. \& Wong, M.S. (2013). Hydrodechlorination catalysis of Pd-on-Au nanoparticles varies with particle size. J. Catal. 298, 206-217. http://dx.doi.org/10.1016/j. jcat.2012.11.005

14. Meshesha, T.B., Barrabés, N., Llorca, J., Dafinov, A., Medina, F. \& Föttinger, K. (2013). PdCu alloy nanoparticles on alumina as selective catalysts for trichloroethylene hydrodechlorination to ethylene. Appl. Catal. A 453, 130-141. DOI: 10.1016/j.apcata.2012.12.019.

15. Bonarowska, M., Pielaszek, J., Juszczyk, W. \& Karpiński, Z. (2000). Characterization of $\mathrm{Pd}-\mathrm{Au} / \mathrm{SiO}_{2}$ catalysts by X-Ray Diffraction, Temperature-Programmed Hydride 
Decomposition and catalytic probes, J. Catal. 195, 304-314. DOI: $10.1006 /$ jcat.2000.2989.

16. Legawiec-Jarzyna, M. Śrębowata, A.; Juszczyk, W. \& Karpiński, Z. (2004). Hydrodechlorination over Pd-Pt/ $\mathrm{Al}_{2} \mathrm{O}_{3}$ catalysts - A comparative study of chlorine removal from dichlorodifluoromethane, carbon tetrachloride and 1,2-dichloroethane. Appl. Catal. A 271 (1-2), 61-68. DOI: 10.1016/j. apcata.2004.01.036.

17. Legawiec-Jarzyna, M., Juszczyk, W., Bonarowska, M., Kaszkur, Z., Kępiński, L., Kowalczyk, Z. \& Karpiński, Z. (2009). Hydrodechlorination of $\mathrm{CCl}_{4}$ on Pt-Au/ $/ \mathrm{Al}_{2} \mathrm{O}_{3}$ catalysts. Top. Catal. 52, 1037-1043. DOI: 10.1007/s11244-009-9258-5.

18. Ichikawa, S., Poppa, H. \& Boudart, M. (1985). Disproportionation of $\mathrm{CO}$ on small particles of silica-supported palladium. J. Catal. 91, 1-10. http://dx.doi.org/10.1016/00219517(85)90282-9

19. Sárkány, A., Horváth, A. \& Beck, A. (2002). Hydrogenation of acetylene over low loaded $\mathrm{Pd}$ and $\mathrm{Pd}-\mathrm{Au} / \mathrm{SiO}_{2}$ catalysts. Appl. Catal. A 229, 117-125.

20. Bonarowska, M. \& Karpiński, Z. (2008). Application of the $\beta-\mathrm{PdH}$ decomposition for characterization of supported palladium catalysts. Pol. J. Chem. 82, 1973-1980.

21. Ziemecki, S.B., Michel, J.B. \& Jones, G.A. (1986). Hydride formation as a measure of alloying in bimetallic systems containing palladium. React. Solids 2, 187-202. http://dx.doi. org/10.1016/0168-7336(86)80082-1

22. Gao, F. \& Goodman, D.W. (2012). Pd-Au bimetallic catalysts: understanding alloy effects from planar models and (supported) nanoparticles. Chem. Soc. Rev. 41, 8009-8020. DOI: $10.1039 / \mathrm{c} 2 \mathrm{cs} 35160 \mathrm{a}$.

23. Bonarowska, M., Machynskyy, O., Łomot, D., Kemnitz, E. \& Karpiński, Z. (2014). Supported palladium-copper catalysts. Preparation and catalytic behavior in hydrogen-related reactions. Catal. Today, corrected proofs on-line: http://dx.doi. org/10.1016/j.cattod.2014.01.029

24. Śrębowata, A., Lisowski, W., Sobczak, J.W. \& Karpiński, Z. (2011). Hydrogen assisted dechlorination of 1,2dichloroethane on active carbon supported palladium-copper catalysts. Catal. Today 175, 576-584. DOI: 10.1016/j.cattod.2011.03.038. 